\title{
A Conceptual Framework for Managing Risks in Public Private Partnership Projects in Housing Estate Development in Nigeria
}

\author{
Yakubu Nehemiah Sanda (Corresponding Author) \\ Department of Estate Management \\ Faculty of Environmental Sciences \\ University of Jos \\ Nigeria \\ E-mail: sanda_yakubu@yahoo.com \\ Natalia A. Anigbogu \\ Department of Building \\ Faculty of Environmental Sciences \\ University of Jos \\ Nigeria \\ E-mail: natashaanigbogu@yahoo.com
}

Received: August 12, 2015

doi:10.5296/ijrd.v3i1.8144
Accepted: October 22, 2015 Published: January 7, 2016

URL: http://dx.doi.org/10.5296/ijrd.v3i1.8144

\begin{abstract}
Construction projects are subject to various uncertainties that impact on achieving the project objectives. This is most apparent in the case of PPP projects due to the number of contracting parties with conflicting interests. Effective risk management in such projects becomes crucial. This paper presents a conceptual framework for managing risks in PPP projects for housing development in Nigeria. The purpose of the conceptual framework is to use it for further studies. The conceptual framework is based on extensive review of related literature in the area of PPP and risk management. It identifies the essential variables for the study. The paper described some major characteristics of PPPs as well as the processes involved in their
\end{abstract}


risk management. The study concludes that, PPPs are most effective when there are adequate legal and regulatory frameworks for smooth operation of PPPs, and the risks sharing structure is spelt out clearly in the contract with adequate measures for enforcing the provisions should any of the contracting party default.

Keywords: Conceptual Framework, Managing Risks, Public Private Partnership Projects, Nigeria

\section{Background of the Study}

Government direct approach to housing delivery adopted by most countries of the world has over the years proved inefficient and ineffective. In numerous cases, it has failed to deliver the required housing both in qualitative and quantitative terms. This has fuelled the search for alternative ways of housing delivery by countries at all levels of development. As a result, attention of many governments has been shifted to collaborative efforts between the public agencies and private sector organizations, which have led to different forms of partnerships.

The basic assumption behind PPP is that in collaboration, the strength of one sector will help to overcome the weakness of the other sector thereby increasing efficiency and effectiveness in the delivery of basic services. For instance, studies have revealed that the bureaucratic and hierarchical nature of public sector often presents a challenge to producing low-cost shelter; it also lacks the flexibility and ability to innovate and to respond quickly to new opportunities and circumstances but is good in setting the overall legal and regulatory framework within which other actors can play their part more effectively (Pyne, 1998). The private sector on the other hand, operates on the basis of adequate returns to investment which has limited its involvement in low-income shelter in the cities of developing countries. The commercial private sector has not been to provide housing at a price that the poor can afford. Furthermore, the commercial private sector is, and always has been the main provider of housing, and has a real comparative advantage in doing so (UNCHS, 1993). PPP therefore is expected to produce results that, neither of the parties can achieve on their own given the same amount of resources (Payne, 1998).

Like any other construction business, PPP arrangement is not without risk. Carbonara, Costatino, Pellegrino and Sciancalepore (2011) reported that, PPP projects have more inherent risks than the traditional method of procurement due to the involvement of many stakeholders with varied interests in addition to the economic, political, social and cultural conditions where the projects are to be undertaken, which are the traditional sources of risk. These PPP related risks need to be studied and managed. Hence, risk management is a necessary condition for a successful PPP projects which have been adjudged to be riskier than the traditionally procured projects. This understanding has triggered numerous researches in the area of risk management.

Some studies have concentrated on developing framework for managing risks in construction, some are concerned with determining the success factors for risk management in PPP, while some considered managing risks in infrastructure projects in general (Awodele, 2012). These studies however, did not provide the desired concept of PPP nor the structure which serves as 
the blue print for managing risks in PPP. This paper is an attempt at filling this gap. The objectives of the study are: to identify the essential variables for a successful PPP project; to identify the essential risks in PPP in housing development and to established a step-by-step procedure for managing risks in construction with particular reference to PPP in housing.

The need for the study is born from the understanding that PPP in housing is seen as a new innovation and adopting the concept to housing estate development is new in Nigeria. In addition, project risks vary from country to country and within the same country they may vary from region to region and are also project dependent. As a result, frameworks developed and applied in other countries or places may not be effective for the same purpose in Nigeria. The purpose of this paper is to develop a conceptual framework for risk management of PPP projects for housing estate developments in Nigeria and to use it for further studies.

\section{Review of Related Literature}

This section reviews literature related to the study. The essence is to consider some definitions of PPP as well as risk with the purpose of determining the implications of such definitions on PPP arrangements. In addition, the literature review was undertaken so as to identify the essential variables of PPP which further used for the development of the framework.

There are several definitions of PPP as there are different perceptions of the concept. as a result there is no common definition of a Public Private Partnership. The City of Calgary (2008) defines PPP as a contractual arrangement between a public authority and a private entity for the provision of infrastructure and/or services in which the private partner assumes the responsibility for financing part or all of the project, the public partner seeks to transfer the project risks to the private partner who has the ability to manage those risks better and the arrangement usually extends beyond the initial construction of the project to involve management. This definition suggests a collaborative effort between the public sector and private partner(s) for the purpose of project delivery in which benefits and responsibilities accruing from the execution of such projects are shared between the parties so involved.

In a typical PPP arrangement, the public sector party performs part or all of a government's service delivery functions and assumes associated risks for a significant period of time in return for benefits/financial remuneration according to predetermined performance criteria (Republic of Ghana, 2011). Most often, these collaborations are based on the principles of comparative advantage because PPP recognizes that there are some activities that the public sector does best and others, where the private sector has more to offer (Pessoa, 2006). The overall aim of PPP is to structure the relationship between the public and private sectors in such a way that the risks associated with the specification, delivery and regulation of public services are allocated to the best party able to management them.

This is informed by the fact that, PPP like other construction activities is not risk free. These risks are enormous and will have tremendous effect on the project objectives if not properly tackled. The overall process of dealing with risk identifying and responding to risk in a project is referred to as risk management. It is one of the most critical project management 
practices and is directly related to successful project completion. Effective risk management is all about striking a balance between risk and opportunities; it is a continuously monitored, integrated into formal process for defining objectives, identifying sources of uncertainties, analyzing these uncertainties and formulating managerial responses in order to produce an acceptable balance between risk and opportunities (Thevendran \& Mawdesley, 2004).

In summary therefore, the study identifies PPP variables. Some variables relate to PPP arrangement such as the characteristics, operating environment and PPP outcome. Some variables concern risks in PPP projects while others relate to risk management in PPP projects.

\section{Development of Conceptual Framework}

The basic features of PPPs are collaborations among public, private and third sectors in joint decision-making, resource commitment, sharing of responsibilities, risks and benefits, a division of labour and comparative advantage as well as interdependence (UNCHS, 1993). In PPP housing for instance, the collaborating parties have different organizing principles and exhibit different strengths (comparative advantages) which determine the role of the contacting parties in the shelter process. The public sector provides, among others accountability/transparency, institutional and regulatory framework, all in an attempt to provide conducive environment for a successful partnership. The private sector on the other hand, provides technical expertise, managerial skills and financial capacity among others (UNHCS, 1993; Silvester \& Araujo, 2012). The implementation and outcome of PPP projects are influenced by a number of factors such as the characteristics (composition, aim and objectives, the roles of the partners) of PPPs and the political, economic, socio-cultural, technological and other contextual situations within the operational area of the PPPs (Hammami et al., 2006 in Ibem, 2010).

The foregoing discussion suggests that an adequate framework for risk management in PPP in housing development requires in-depth knowledge on the PPP arrangements for housing, specific risks in PPP projects, and risk management in PPP housing. Based on this, the conceptual framework for the study is developed in three basic stages covering the characteristics of PPP for housing estate development, PPP risks and risks Management in PPP (Figure 1). 


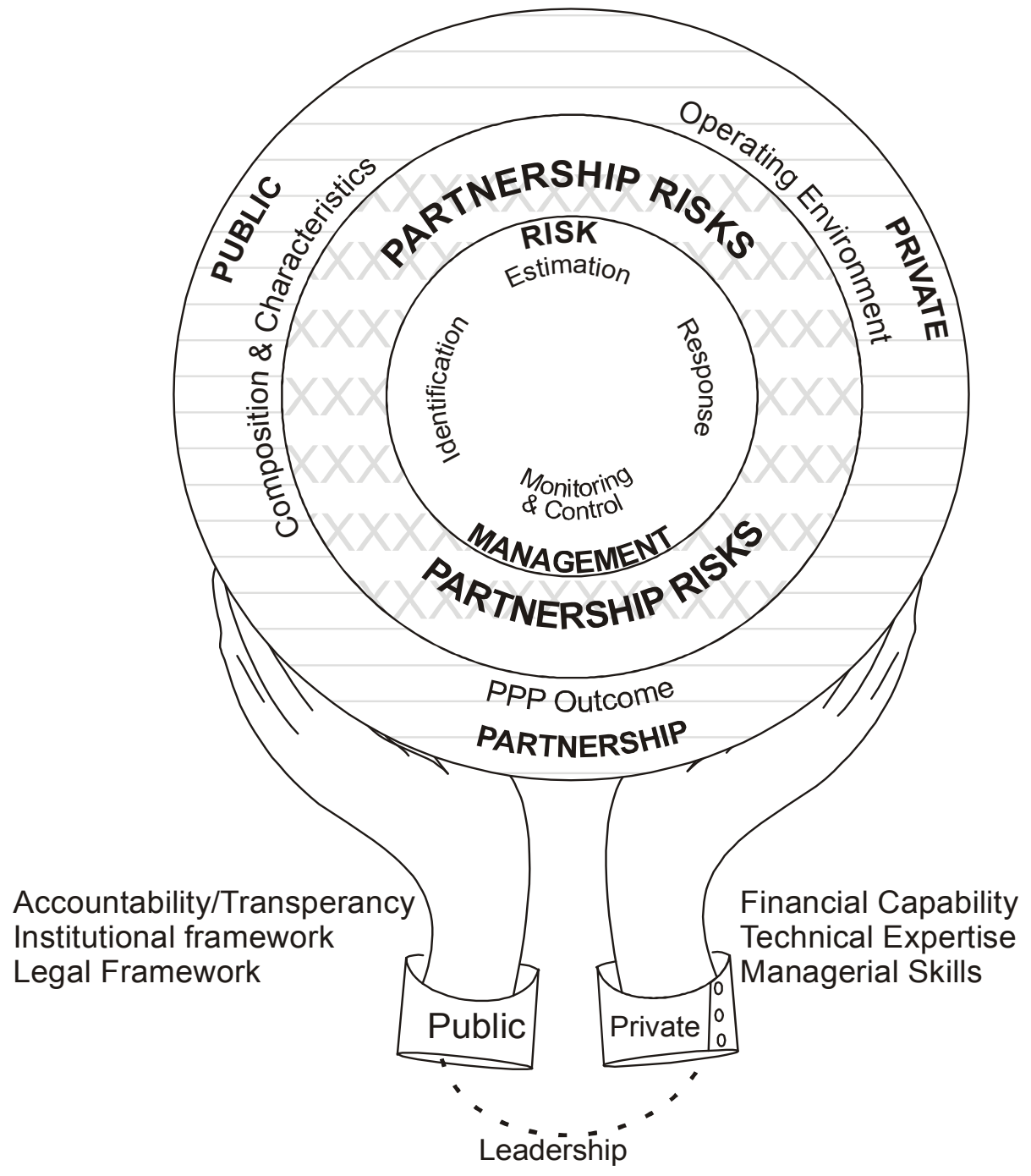

Figure 1. Conceptual framework for managing risks in PPP in housing development

\subsection{Characteristics of PPP}

This section is represented by the outer layer of the research framework and it focuses on some key elements of PPP arrangements (Figure 1). These elements are identified through thorough analysis of PPPs. In assessing the role of government agencies in PPPs in housing delivery in Nigeria, Ibem (2010) stressed that, PPP projects are generally characterized by the PPP structure, the contextual and intervening factors sometimes referred to as operating environment (Yang, Hou, \& Wang, 2013) and PPP outcome. These characteristics were adopted and used in the development of this framework.

\subsubsection{PPP Structure}

The PPP structure comprises of numerous variable depending on the need and complexity of the project. Regardless of the complexity, the structure of any PPP arrangement is significantly influenced or shaped by its model or contract type (Carbonara et al., 2011). PPP 
comes in wide variety of models such that, there is often no clear agreement on what does and what does not constitute a PPP form (Hemming, 2006). It is therefore important to examine the model adopted in each PPP arrangement. The model defines the roles of the contracting parties with respect to design, construction, financing, operating and maintenance of the asset. It also helps in specifying who is responsible for what risk and how the private party recoups its expended fund.

Based on the degree of legal regulations, The European Commission (2004) grouped PPPs into contract PPPs, concession PPPs and institutional PPPs. Contract PPPs are more legally regulated in nature and are subject to detailed Community regulations. They are based upon a classical principal-agent relationship written into a contract. The public party pays the private party a monthly, quarterly, or annual unitary payment for the service, building or infrastructure over the long-term contract period. Examples of contract PPPs include DBFOM, DBFO, DBF, among others. Concession-PPPs are non-priority public works or public services contracts, and are only sparsely regulated in secondary legislation. Concession PPPs are also based upon a contractual relationship, but here the asset is fully transferred to a private concessioner that either collects direct charges from the users of the asset or collects unitary payments from the public partner. Institutional PPPs involve shared public-private ownership of an asset with public and private partners each holding shares.

Of equal importance to the PPP model, is contract duration. Partnerships are formed for the mutual benefits of the contracting parties. The public sector aims at exploiting the private sector's resources and expertise in the provision and delivery of public service and, accordingly, improving the efficiency and quality of services (Carbonara et al., 2011). The private sector seeks to take advantage of the stable environment provided by the public sector to invest with the purpose of making future gains. The EC (2004) stressed that, PPP contracts require adequate length of time in order to afford the private party the opportunity to make worthwhile investment and to recoup its capital. Hence, contract duration becomes an important variable in characterising PPP arrangements. The PPP relations generally last long, usually between 25-30 years.

Another important defining element of the PPP structure is the aspect of project financing. It therefore becomes imperative to assess the financing structures for the purpose of determining the funding mixes used in PPP arrangements. Fundamentally, one of the aims of PPP is to bring the private sector's finance as well as management skills into the provision of facilities and services traditionally delivered by public sector. The financial elements would include the sources of funding, interest rate, capital structure, repayment and drawn down schedules, currency of loans and payments (Li, Akinyoye \& Hardcastle, 2000). The financing structure could be through equity, debt financing or a mixture of both. The two extreme cases of PPP financing are total equity and total debt financing. In general, PPP projects are financed using a combination of both with varying ratios of equity to debt. Usually, debt financing exceeds 70\% (Ye, 2009 in Carbonara et al., 2011). Each kind of fund is exposed to different level of risks and therefore requires different returns. An attractive financial package demands: the financial charges and interest rates of the package must be low (low cost); the package is dependent on sound and efficient financial planning and analysis by reputable 
bankers (credibility); minimal financial risks to the Government; and minimal burden on the debt-servicing capacity of project revenues (Li, Akintoye, \& Hardcastle, 2000).

Risk sharing formula between the two sectors is another important variable that helps define the structure of a typical PPP arrangement. The risks associated with PPP can be grouped into two broad categories: endogenous (directly related to the project) and exogenous (outside the scope of the project occasioned by external factors) risks. Most risks are exogenous, thus the private partner is not better informed about this risk than the public partner, nor can it manage it better. The public party therefore is required to insulate or isolate the contractor from these kinds of risks (Zaharioaie, 2012). It is advisable that the risks should be shared based on the benefits perceived by each associated part of the project and should be allocated to the party that is best able to manage them (Carbonara, Costantino, \& Pellegrino, 2013). The private sector considers a partnership to be attractive when the state assumes a significant part of the risks or offers more significant risk premiums because investors will invest only when the risks will be lower than the profit expected to be obtained from the project. Moreover, the accuracy of the presumed transfer of a package of risks to the private sector, together with the identification and valuation of risks are essential to the construction of a meaningful PPP project (Jin, 2009). It is required that, the risk sharing should be fair and determined by the responsibilities of each party assumed through the contract.

\subsubsection{The Operating Environment for PPP}

An efficient PPP arrangement demands a favourable environment to ensure that production costs and public restraints are reduced to a bearable level. The operating environment is composed of at least two essential elements: the presence of laws and anticorruption mechanism (Yang, Hou, \& Wang, 2013) which could be reduced to legal and institutional frameworks for regulating the operation of the PPP arrangements. The existence of enforceable laws provides assurance to private partners for safeguarding their interests and alleviating risk and at the same time help in curbing opportunistic behaviours in PPP. A sound legal system also assists in ensuring the efficient operation of partnerships in accordance with broader policy objectives while the absence of same breeds insolvable disputes (Grimsey \& Lewis, 2004). The anticorruption mechanisms cover institutions put in place to reduce corruption by instilling transparency in PPP arrangements. Corruption is defined as the exercise of public power for either private gain or state capture (REF). Corruption frequently occurs in PPPs in which the government supervision agency or its affiliate is also a partner (investor or party of interest) in the project. Corruption imposes heavy transaction costs on private partners. Anticorruption measures include the improvement of openness, fairness, and transparency in the bidding process; the enforcement of the supervision of operation; and the strengthening of performance, evaluation, and auditing (Neshkova \& Kostadinova, 2012 in Yang, Hou, \& Wang, 2013).

Next to anticorruption is credibility of the participating government. Credibility is very important in attracting private investment. Government credibility is enhanced by factors such as availability of political checks and balances, an independent juridical system, and independent regulation. In transitional economies, lack of credibility among participating 
governments has been a serious issue in PPP implementation (Yang, Hou, \& Wang, 2013). Some governments in transitional economies promise more than they can deliver to attract foreign investment (Ho, 2006). A successful PPP requires a strong central administration structure to steer and guide policy implementation. This underscores the need for good governance as a prerequisite for successful PPPs. According to Badshah (1998) in Li, Akintoye and Hardcastle (2000), good governance is participatory, transparent and accountable and has the following characteristics which have far implications in the performance of PPP arrangements.

Closely linked to credibility of the participating government is the political environment. Political support is another necessary requirement for a successful PPP. Private partners would always require some sort of immunity from unnecessary political interference. This is due to the fact that the public-private partnership contract is closed on a long period of time under which major political changes could occur. In an event of change in government, the private sector may face the political risks such as contract expropriation or unilateral termination of the contract. Zaharioaie (2012) opined that, the public-private partnership contract not being under the auspices of the commercial law, can be discretionary modified by the public authorities against the private partner. The private investors therefore, will be more attracted by investments in stable states from a political point of view. This is because the risks that are supported by the state are in most of the cases are the ones that the private operators have little control of, such as political, financial and usage risk.

In addition, availability of market for PPP products is equally important for a successful PPP arrangement. In order to develop an effective PPP, a market must exist such that PPP projects are profitable to undertake, the private party is willing to participate and the financial market is willing to invest (Yang, Hou, \& Wang, 2013). Hence successful PPP arrangement requires a strong market structure to support profitability goal of the private sector. The market structure can be characterized by the level of demand of the sector and the level of supply which is a function of the level of competition (Carbonara, Costantino, \& Pellegrino, 2013). Demand-side analysis examines characteristics of the client base such as providers' sources of funding and pricing strategies and the technology adopted in service or asset delivery while the supply-side analysis assesses the market through willingness-to-pay studies that give information on consumers' preference, household sources of income, and public sector's current target population among others. For instance, in PPP housing the private party will desire that, there is readily available demand for the housing units to be produced. In occasions where low demand is envisaged, the private party demands for a kind of immunity in the form of either bank guarantee or subsidy to ensure they will not be left with unsold products at end of the contract period. By combining both demand- and supply-side analysis, service delivery strategies can be developed to address inefficiencies and create opportunities for greater private sector participation (USAID, 2010).

\subsubsection{PPP Outcome}

The outcome explains the overall expectations of the entire PPP arrangement. An integral component of all PPP negotiations is the project output. As part of the contractual 
arrangement, the parties agree on who should be responsible for what and targets are set for each party to achieve at the end of the contract. For instance in PPP for housing estate development, the expected outcome covers items such as the number of PPP housing scheme, characteristics of housing units, targeted population and type of housing scheme (Ibem, 2010). Given that PPPs are geared towards the provision of public goods and or services, the output from these kinds of cooperation is always public or at least quasi-public in nature (Nsasira, Basheka \& Oluka, 2013).

\subsection{Public Private Partnership Risks}

The second layer of the framework (Figure 1) is represented in this section discusses the risks associated with PPP projects generally and in housing estate development in particular. This becomes a necessary part of the framework because not all PPP projects are successful as unexpected major problems can often arise during any stage of the project which jeoperdising the achievement of the project objectives. Tadayan, Jaafar and Nasri (2012) summerised the most serious effects on project objectives as follows: failure to keep within cost estimate, failure to achieve the required estimation time and failure to achieve the required quality and operational requirements. These unexpected events that when they occur will affect the project objectives represent the project risks.

Traditionally, risk was viewed as an agent of damages, dangers and negativity such that when it occur it affects the project negatively (Chiken \& Posner, 1988 in Zou, Zhang \& Wang, 2007). However, recent researches tend to emphasize the two-edged nature of risk such as threats and challenges on one hand or opportunities and threats on the other (Flanagan \& Norman, 1993; Bolai \& Price, 2003). In other words, the impact of risk is not necessary negative; it can also bring positive influence or some profitable results on the project objectives. The understanding of what risk is and is not informs the perception of organization towards risk and determines place of risk management in such organizations.

The origin of risk is the uncertainty inherent to any project and every risks is associated with (at least) a cause, a consequence (if it occurs), and the probability or likelihood of the event occurring (Cano and Cruz, 2002). Project risks can be categorised into internal or external (Kolhaktar \& Dutta, 2013). An internal risk is unique to a project and is caused by sources inherent in the project; example can be the inability of a product to function properly. Whereas, an external risk has origin in sources external to the project scope, such as cost cuts by senior management. Akelere and Gidado (2003) examined the implementation of PPP/PFI in Nigeria and reported that, the top 10 risks factors common in implementation of PPP include political risk, inflation risk, currency risk, completion risk, regulation risk, availability risk, operation risk, technology risk, market risk (demand) risk and resources risk. These risks associated with PPP projects must be properly identified and efficiently managed to guarantee project success.

\subsection{Managing Risks in PPP Housing Estate Development Projects}

This section is represented by the inner circle on the framework (Figure 1) which is the core of the research. This is needful because risk management is one of the core issues in ensuring 
success in construction projects, including PPPs. This section therefore shall discuss the key elements of the risk management process.

The subject of risk management has been studied by several researchers and a variety of risk management models with different numbers of stages can be found in the literature (Cano \& Cruz, 2002; Flanagan \& Norman, 1993; Project Management Institute (PMI), 2004; Baloi \& Price, 2003). Regardless of the variation in these models, there are key elements that are seen as core in the risk management process and they include risk identification, risk estimation, risk response and risk monitoring and control. Therefore in this framework, risk management is discussed in light of these four stages.

Risk identification is the first step of the risk management process. In order to manage risk, an organization needs to know what risks it faces. This helps to determine the risks that might affect the project and document their characteristics. The identification of risk can be separated into initial and continuous risk identification. Initial identification is for new projects or activity within an organization for which the risks have not been identified. Continuous risk identification is for ongoing project in order to identify new risks which did not previously arise, changes in existing risks in the course of the project, or risks which did exist ceasing to be relevant to the organization (HM, 2004).

It is likely that a large number of risks may be identified in a particular project. These risks will not all be independent of each other; rather they will typically form natural groupings. All risks, once identified, should be assigned to an owner. It is not enough to only identify a risk, but it should also be made clear who is responsible for that risk. The identification process should not focus only on events that will affect the projects negatively, but should also include those events that will positively influence project outcome since modern risk approaches also focus on opportunities. Jutte (2014) reported that many of project identification teams are overloaded with work thereby creating a project dynamics where only negative risks matter. It is therefore important to also take time to consider opportunities as well because there are chances identifying opportunities with high pay-off that do not require a big investment in time or resources (Cano \& Cruz, 2002).

Quite a number of risk identification techniques and tools are available to be explored by the identification team. These methods include document review (review of project documents); information gathering (brainstorming, Delphi technique, interviewing, root cause analysis, SWOT (strength, weakness, opportunities and threats) analysis; checklist analysis; assumption analysis; and diagram techniques (cause-and-effect diagrams, process flow charts and influence diagrams) in order to identify the interrelationships between activities, risks, consequences and responses (PMI, 2004). The identified risks, especially those that require further actions are penciled down for assessment and analysis which Klemetti (2006) refered to as risk estimation.

The estimating stage focuses on calculating the degree of uncertainty associated with risks by combining both likelihood of the risk being realised, and of the impact if the risk realised. The estimation stage therefore deals with determining the probability of occurrence and severity of impact of each identified risks, prioritizing risks for further attention, grouping 
risks into categories to identify hot spots of risk exposure or common causes and analyzing the combined effect of risk on objectives using statistical models (Hillson, 2006). Since different risks have different impacts on project objectives, the risk manager or management team needs to prioritise the identified risks for further action.

In risk prioritization, the organization determines which combinations of probability and impact result in a classification of high risk (red condition), moderate risks (yellow condition) and low risks (green condition) (PMI, 2004). Prioritising risks serves as guide to risk response because it points out the risk that requires much attention and those that can just be kept under watch by the organization. The highest priority risks should be given regular attention at the highest level of organization (HM, 2004).

Sequel to risk identification and estimation is risk response. This process is directed at identifying a way of dealing with the identified and assessed project risks. It deals with developing options, and determining actions to enhance opportunities and reduce threats to the project objectives. Implementing this plan of action is the activity that actually adds value to the project (Jutte, 2014). The risk management team will have to decide on which response measure to adopt taking into account the criticality of the risks to the project objective as revealed by the preceding stages of identification and estimation.

Four main risk response measures are found in the literature. Though these strategies are referred to differently in literature, the most common nomenclature used for these response strategies are: risk avoidance, risk reduction, risk transfer and risk acceptance (Flanagan and Norman, 1993; Klemetti, 2006). Risk avoidance deals with the risks by changing the project plan or finding methods to eliminate the risks such as adopting a different technology or terminating the project. Risk reduction aims at reducing the probability and/or consequences of a risk event. Those risks that remain in the project after risk avoidance and reduction may be transferred to another party either inside or outside the project. Risk retention or acceptance indicates that the risk remains present in the project (Osipova, 2008). Different studies have reported variations in the adoption of these response measures. For instance, risk reduction has been identified as the most frequently used technique within the construction industry in Sweden, while risk transfer is the most preferable strategy among the UK practitioners (Akintoye and MacLeod 1900; Skitmore 2004, Tang et al. 2007 in Osipova, 2008).

The implementation of these response strategies requires proper monitoring to ensure there is no deviation from the original plan. Risk monitoring and control is a process of identifying, analyzing, and planning for newly arising risks, keeping track of the identified risks and those on the watch list, reanalyzing existing risks, monitoring trigger conditions for contingency plans, monitoring residual risks, and reviewing the execution of risk responses while evaluating their effectiveness (PMI, 2004). The purpose of this stage is to determine if: project assumptions are still valid, risks as assessed has changed, proper risk management policies and procedures are being followed. These become necessary so as ensure the successful implementation of the project with a guarantee degree of success. 


\section{Conclusion}

PPP emerged as a Policy initiative to attract and encourage private sector participation upon realization that neither the government nor the private sector can provide the adequate housing required. PPP arrangements can take many forms but like other construction projects are not without risks. These risks may stem from the relationship between the contracting parties or from the project environment. While a successful PPP projects strongly rely on its operating environment such legal requirement and political support, it also demands that these risks be effectively managed to guarantee project success. This can be achieved with a good framework in place which the study attempt to develop. The developed conceptual framework provides a step-by-step approach to managing risks in PPP for housing estate development. The framework starts with the characteristics of PPP, the risks factors associated with PPP housing and the management of risks in PPP arrangements.

\section{References}

Akerele, D., \& Gidado, K. (2003). The Risks and Constraints in the Implementation of PFI/PPP in Nigeria. In D. J. Greenwood (Ed.), 19th Annual ARCOM Conference (pp. 379-391). Univerisy of Brighton: Association of Researchers in Construction Management. Awodele, O. A. (2012). Framework for Managing Risk in Privately Financed Market Projects in Nigeria. Retrieved from http://www.ros.hw.ac.uk/...am/10399/2571/1/

Bolai, D., \& Price, A. D. (2003). Modelling Global Risk Factors Affecting Construction Cost Performance. International Journal of Project Management, 21, 261-269.

Cano, A. D., \& Cruz, M. P. (2002). Integrated Methodology for Project Risk Management. Journal of Construction Environment and Management, 128(6), 473-485.

Carbonara, N., Costantino, N., \& Pellegrino, R. (2013). A Three-Layer Theoretical Framework for Analyzing Public Private Partnerships: The Italian Case. Organization, Technology and Management: An International Journal, 6(2), 799-810.

Chapman, C., \& Ward, S. (2004). Why Risk Effeciency is a Key Aspect of Best Practice Projects. International Journal of Project Management, 22, 619-632.

European Commission. (2003). Guidelines for Successful Public Private Partnerships. Brussels.

Flanagan, R., \& Norman, G. (1993). Risk Management and Construction. Oxford Blackwell Scientific Publications.

Grimsey, D., \& Lewis, M. K. (2004). Public Private partnerships: The Worldwide Revolution in Infrastructure provision and project finance. Chaltenham, UK: Edward Elgar.

Hemming, R. (2006). Public Private partnerships, Government Guarantees, and Fiscal Risk. Washington, DC: International Monetary Fund.

Hillson, D. (2006). Integrated Risk Management as a Framework for Organisational Success. 
HM Teasury. (2004). Management of Risk: Principles and Concept. The Orange Book (Revised Version).

Ho, P. H. (2006). Development of Public Private Partnerships (PPP) in China. Surveyors Times, 15(10).

Ibem, E. (2010). An Assessemnt of the Role of Governemnt Agencies in Public Private Partnerships in Housing Delivery in Nigeria. Journal of Construction in Developing Countries, 15(2), 23-48.

IEC. (2001). Project Risk Management-Application Guidelines. International Standard. Geneve: IEC. Retrieved from http://www.standardsuk.com/products/BS-IEC-62198-2001.php

Jin, X. H. (2009). Allocating Risks in Public Private partnerships Using a Transaction Cost Economics Approach: A Case Study. The Australian Journal of Construction Economics, $9(1)$.

Jutte, B. (2014). 10 Golden Rules of Project Risk Management.

Klemetti, A. (2006). Risk Management in Construction Project Networks. Helsinki University of Technology, Laboratory Industrial management.

Kolhatkar, M., \& Dutta, A. B. (2013). Study of Risk in Construction Projects. Global Research Analysis International, 2(9), 104-107.

Li, B., Akintoye, A., \& Hardcastle, C. (2000). Coceptual Framework for Construction Public Private partnerships. 16th Annual ARCOM Conference. Glasgow Caledonian Univeristy: Association of Researchers in Constuction Management.

Nsasira, R., Basheka, B. C., \& Oluka, P. N. (2013). Public Private partnerships (PPP) and Enhanced Service Delievry in Uganda: Implications from the Energy Sector. International Journal of Business Administration, 4(3), 48-60.

Osipova, E. (2008). Risk Management in Construction Projects. Lulea University of Technology, Division of Architecture and Infrastructure, Department of Civil, Mining, and Environmental Engineering. Licentel Thesis.

Payne, G. K. (1999). Making Common Ground: Public-Private Partnerships in Land for Housing.

Pessoa, A. (2006). Public Private Sector Partnerships in Developing Countries: Prospects and Drawbacks. Faculdade de Economia do Porto.

Project Management Institute (PMBOK). (2004). A guide to the Project Management Body of Knowledge (3rd ed.). Four Campus Boulevard, Newton Square, USA.

Republic of Ghana. (2011). National Policy on Public Private Partnerships (PPP): Private Participation in Infrastructure and Services for Better Public Service Delievry.

Silvester, H. C., \& Aroujo, J. F. (2012). Public Private Partnerships / Private Finance Initiatives in Portugal: Theory, Pactice, and results. Public Performance and Management 


\section{Macrothink}

International Journal of Regional Development ISSN 2373-9851 2016, Vol. 3, No. 1

Review; 36(2) , 316 -339. Tadayan, M., Jaafar, M., \& Nasri, E. (2012). An Assessment of Risk Identification in Large Construction Projetcs in Iran. Journal of Construction in Developing Countries, 57-69.

The City of Calgary. (2008). Public Private partnerships Council policy Framrwork. Retrieved from http://pppcouncil.ca/pdf/calgary_p3policy_122008.pdf

Thevendran, V., \& Mawdesley, M. J. (2004). Perception of human Risk Risk Factors in Construction Projects: An Exploratory Study. International Journal of Project Management, 22, 131-137.

UNCHS. (1993). Public Private Partnerships in Enabling Shelter Starategies. Retrieved from http://www.worldcat.org/publicprivate-partnerships

United Agency for International Development (USAID). (2010). Fostering Public Private Partnerships to Reduce Health Inequalities in Peru. USAID. Retrieved from http://lup.lub.lu.se/record/2544507/file/2544515.pdf

Yang, Y., Hou, Y., \& Wang, Y. (2013). On the Development of Public Private Partnerships in Transitional Economies; An Explanatory Framework. The American Society for Public Administration, 73(2), 301-310.

Zaharioaie, M. (2012). The Utility of Using Public Private Partnership for Local Governments. Journal of Public Administration, Finance and Law, 17-24.

Zou, P. X., Zhang, G., \& Wang, J. (2007). Understanding the Key Risks in Construction Projects in China. International Journal of Project Management, 25, 601-614.

\section{Copyright Disclaimer}

Copyright for this article is retained by the author(s), with first publication rights granted to the journal.

This is an open-access article distributed under the terms and conditions of the Creative Commons Attribution license (http://creativecommons.org/licenses/by/3.0/). 